\title{
The Monday Effect Revisited: A Diary and Sleep Actigraphy Study
}

\author{
Achim Elfering $^{1,2}{ }^{-} \cdot$ Christin Gerhardt $^{1,2} \cdot$ Diana Pereira $^{3} \cdot$ Anna Schenker $^{1} \cdot$ Maria U. Kottwitz $^{1}$
}

Received: 25 March 2020 / Revised: 24 August 2020 / Accepted: 30 August 2020 / Published online: 22 September 2020

(c) The Author(s) 2020

\begin{abstract}
Purpose Accidents are more likely to occur during the morning hours of Mondays (Monday effect). This might be due to a higher level of cognitive failure on Monday morning at work.

Methods In a pilot actigraphy study across one working week, we explored this Monday effect and regressed daily selfreported workplace cognitive failure on weekdays (Monday versus other days), background social stressors at work, delayed sleep onset and sleep duration. Diary data were gathered from 40 full-time employees.

Results Confirming our assumptions, results revealed work-related cognitive failure and sleep-onset latency on the previous night to be higher on Mondays compared to other workdays. Work-related cognitive failure correlated positively with delayed sleep-onset latency and background social stressors. In multilevel regression analysis, Monday significantly explained variations in workplace cognitive failure. The addition of background social stressors at work and sleep-onset latency to the regression model showed unique contributions to the prediction of workplace cognitive failure. No significant two-way or three-way interactions between working days, sleep-onset latency or sleep duration, and background social stressors were found.

Conclusion Peak levels of cognitive failure on Monday morning and the association of cognitive failure with social stressors at work contribute to understanding the mechanisms involved in the increased prevalence of occupational accidents on Monday morning. Occupational safety interventions should address both social stressors at work and individual sleep hygiene.
\end{abstract}

Keywords Work stress $\cdot$ Sleep $\cdot$ Diary $\cdot$ Cognitive failure $\cdot$ Safety at work

Achim Elfering

achim.elfering@psy.unibe.ch

Christin Gerhardt

christin.gerhardt@psy.unibe.ch

Diana Pereira

diana.romano@bfh.ch

Anna Schenker

aschenke@its.jnj.com

Maria U. Kottwitz

maria.kottwitz@psy.unibe.ch

1 Department of Psychology, University of Bern, Fabrikstrasse 8, 3012 Bern, Switzerland

2 National Centre of Competence in Research, Affective Sciences, University of Geneva, CISA, Geneva, Switzerland

3 Berner Fachhochschule, Institut Soziale Organisationen, Hallerstrasse 10, 3012 Bern, Switzerland

\section{Introduction}

Safety at work varies across weekdays, and Mondays often show peaks in work accident rates. Wigglesworth [1] analysed data from 750,000 compensation claims on occupational injuries in Queensland, Australia between 1968 and 1988 and found what he called a Monday effect peak in accidents in men and women, i.e. accident rates are decreasing on all other days of the week, with Friday rates being a third lower than Monday rates. This is also reflected in more recent data [2, 3]. In Switzerland, the accident rates reported by the Swiss work accident insurance consistently show a Monday effect [4]. In 2017, the number of accidents at work in Switzerland was 42,227 (19.7\%) on Mondays and fell continuously over the weekdays to Fridays to 36,067 (16.9\%) [5]. Such an accident by weekday analyses was useful for the planning of the health system capacity, e.g. the capacity of emergency departments [6].

The Monday effect is characterized, first, by the fact that the increased risk is limited to the morning hours $[1,5]$. 
Second, the effect appears to be stable over decades, despite many changes in work tasks, working hours and the organizational context, as shown, for example, by a comparison of Swiss accident statistics for 1977 and 2017 [5, 7]. Third, this effect seems to be independent of the overall risk of occupational accidents, which has largely decreased over the last 40 years due to efforts to prevent accidents and technological change. Finally, the Monday effect does not appear to be specifically limited to working time, but also seems to relate to non-work accidents [5]. Therefore, it is unlikely that higher work demands on Monday morning (e.g. extra procedures to start production after the weekend) cause the Monday effect.

We suppose that the Monday effect also manifests itself in cognitive performance. Compared to other days of the week, Mondays, for example, have a higher risk of cell abnormalities being overlooked by diagnostic raters [8] or of railway controllers making mistakes [9]. Many errors at work occur during routine task fulfillment and point to attentional slips or loss of working memory contents [10]. Such workplace cognitive failure has been consistently shown to be an antecedent of near accidents during the commute to work and back home $[11,12]$ and to predict minor injuries at work [13], during sports after work [14] and domestic falls [15]. Hence, we hypothesised more frequent workplace cognitive failure on Monday morning compared to the subsequent working weekdays (Monday Effect; hypothesis 1 (H1)). However, it has not yet been fully understood what might trigger this cognitive failure on Monday. We contribute to previous research on the Monday effect by looking in detail at the association between objectively measured sleep and self-reported social background at work on cognitive failure within this diary study.

\subsection{Monday Morning Blues and Sleep}

We assume that poor night's sleep and social work stressors precede the Monday effect. Interestingly, one might consider Monday morning to be a time when people are fresh and in good mood after they have recovered from work demands over the weekend. However, mood on Monday seems to be lower than on other workdays (Blue Monday), and this difference seems to be rather universal [16]. Lower mood seems to go along with higher fatigue. Rook and Zijlstra [17] reported that mean levels of fatigue were highest on Monday and Tuesday and decreased towards the end of week. Looking at Monday morning, fatigue levels often are highest because individuals have slept in later on the weekend and that "appears to have a subsequent cost of delaying circadian rhythm, delaying sleep on Sunday night and increased daytime sleepiness and fatigue, the so-called Monday Morning Blues" [18].
Thus, sleep duration (i.e. sleep quantity) and qualitative aspects, such as sleep-onset latency might differ on Sunday night. Even when individuals go to bed at their usual weekly time, the shift in circadian rhythm caused by later sleep-in time on Friday and Saturday may cause a delayed sleep onset that results in even a shorter sleep duration during Sunday night and higher fatigue on Monday morning. We hypothesised sleep-onset latency to be longer for the night from Sunday to Monday compared to the following four nights of the working week (H2). Sleep duration is expected to be shorter for the night from Sunday to Monday compared to the following four nights of the working week (H3).

\subsection{Delayed Sleep Onset and Shorter Sleep Duration Under the Magnifying Glass}

Impaired sleep in the current night is a major risk factor for high levels of workplace cognitive failure during the next day. Recently, Crain and colleagues [19] theoretically underlined that sleep quality and quantity have an influence on the attitudes, behaviour and state of a person at work and in private life through depletion of energy and time resources. Good sleep provides physical energy that is needed for waking physical and cognitive activities. Brossoit and colleagues [13] could confirm the model by showing that sleep quantity and quality affect cognitive failure that in turn affects safety-related behaviour. According to Martin [20], workplace cognitive failure can best be defined as a "cognitively based error that occurs during the performance of a task that the person is normally successful in executing" (p. 97). This definition suggests that workplace cognitive failure is not due to reduced ability but rather to lapses in motor function (i.e. the performance of unintended actions, or action slip; [10, 21]). Examples of employee workplace cognitive failure include switching off the car lights unintentionally after having lit them [10]. At best, such errors detract from effective job performance, but at the worst, they can result in disastrous accidents [13, 22]. We hypothesised delayed sleep onset (H4a) and shorter sleep duration ( $\mathrm{H} 4 \mathrm{~b})$ to predict higher workplace cognitive failure on the following morning.

\subsection{Social Work Stressors, Sleep, and the Monday Effect}

The Blue Monday effect was reported to be associated with work-related stressors [23]. In particular, adverse social working conditions have the potential to cause stress through a threat to self [24] and, thus, might shift attention away from the goals of task fulfilment towards goals of self-(worth)-protection hindering cognitive functioning [25]. We hypothesised higher background social stressors at work 
to predict more frequent workplace cognitive failure on the next morning (H5).

Sleep is a process that can allow a person to replenish resources that were used during the day and, thus, to be ready for the new working day $[19,26]$. Thereby, several studies show that social stressors at work cause lower mood and impair sleep even on Sunday, which is presumably caused by anticipation of work problems on the coming Monday [27, 28]. Background social stressors at work and the Monday effect may interact in that the night from Sunday to Monday is potentially more affected by social stressors at work than other nights of the working week. Anticipation of upcoming work problems may play a role here. Hence, we expect a significant interaction effect between Monday and background social stressors on workplace cognitive failure (H6).

In addition, one might also expect a higher-order interaction between the Monday effect, background social stressors at work and sleep duration or sleep-onset latency. A secondorder interaction may indicate a personal factor. Just those participants who experience high background social stressors and have vulnerable sleep show the Monday effect. We test this higher-order interaction in two separate modelsone including sleep-onset latency as part of the higher-order interaction $(\mathrm{H} 7 \mathrm{a})$, and the second including a second-order interaction with sleep duration (H7b).

\section{Methods}

\subsection{Sample and Procedure}

Data collection was done in 2012. Participants had to work on Monday mornings and had to work at least $60 \%$ of a full-time equivalent of a $42 \mathrm{~h} /$ week (at least $25 \mathrm{~h} /$ week). Participants were recruited from a software development and counselling organisation. Among the 192 employees approached, 47 employees agreed to participate (24.5\%). The data of seven participants had to be excluded from the analysis due to technical malfunctions (three participants), lack of wearing comfort (two participants) of the SenseWear bracelet, missing information in the daily questionnaire or due to pregnancy.

Thus, the final sample consisted of 40 participants (22 women) and data from 198 observation days and nights. Mean age was 34 years $(\mathrm{SD}=11.3)$ and 32 participants $(80 \%)$ worked full-time ( $42 \mathrm{~h} /$ week). Of the remaining individuals, two worked at $90 \%$, five at $80 \%$ and one participant at $60 \%$ full-time equivalent. No participants reported having sleep problems, taking sleep medication or suffering from a major physical or mental health problem. To compensate participants for their time and to encourage participation, we offered them individual feedback about their work situation and well-being at the end of the study.

First, research assistants instructed participants face to face on how to use the ambulatory assessment device (SenseWear Armband) and asked them to put them on when they intended going to sleep. In the next step (on Tuesday), the participants filled out an online general questionnaire, which included information on demographics and background social stressors. The next day, participants began completing daily online surveys and the collection of actigraphy data during nights. The daily questionnaire was filled out at noon and asked about workplace cognitive failure during the morning. The questionnaires were merged using a personal code, which the individual had to create him-/ herself. Participants used the continuous ambulatory assessment for one consecutive working week (including the weekend) until Wednesday of the next week.

\subsection{Measures}

Background social stressors at work. Social stressors were measured with eight items assessing social conflicts with supervisors and colleagues [29]. The scale measures interpersonal tensions (e.g. "I had a conflict with the supervisor"), using a 4-point Likert scale that ranged from 1 (not at all) to 4 (very much). Cronbach's alpha was 0.89 .

Daily work-related cognitive failure. Cognitive failure during morning work was assessed at noon with the workplace cognitive failure scale [10]. The scale is regarded as a proxy for the accident risk [10-12] and consists of fifteen items addressing memory (e.g. "Cannot remember whether you have or have not turned off work equipment"), attention (e.g., "Do not fully listen to instructions") and action (e.g. "Throw away something you meant to keep (e.g., memos, tools)"). The response format was 1 (never) to 5 (very often). Cronbach's alpha was 0.85 .

Sleep actigraphy. The term actigraphy refers to methods using miniaturised computerised wristwatch-like devices to monitor movements. ${ }^{1}$ In the current study, the actigraph used

\footnotetext{
${ }^{1}$ Sleep evaluation in humans has usually been performed with PSG, which has been considered the gold standard for detecting sleep impairments in humans [30]. However, in recent decades, actigraphy has become an accepted tool in sleep research and sleep medicine [31]. Actigraphy can be seen as an effective way to provide low-cost, non-invasive, objective and continuous data for the diagnosis of sleep disorders in ambulatory settings [32]. The comparison of actigraphy with PSG has yielded agreement rates between 78 and 95\% [32]. According to a study conducted by Morgenthaler and colleagues [33], actigraphy is a valid way to determine sleep patterns in normal, healthy populations as well as in patients suspected of certain sleep disorders. These findings are corroborated by the results obtained by Germain, Buysse and Kupfer [34], who found that the algorithm correctly identified $93 \%$ of all sleep episodes and $83 \%$ of all wakefulness episodes when compared to EEG measurements in the sleep laboratory.
} 
Table 1 Description of study variables

\begin{tabular}{lllllll}
\hline & \#Items & Response format & Range & $M$ & SD & Cronbach's alpha \\
\hline Workplace cognitive failure & 15 & Likert 1-5 & $1-3.07$ & 1.388 & 0.398 & 0.847 \\
Background social stressors at work & 8 & Likert 1-4 & $1-3.13$ & 1.637 & 0.434 & 0.753 \\
Sleep onset latency & n.a & Minutes & $1-96$ & 14.641 & 14.164 & n.a \\
Sleep duration & n.a & Minutes & $230-840$ & 416.662 & 73.071 & n.a \\
\hline
\end{tabular}

$N=40$ participants assessed during $n=198$ nights

Table 2 Correlation between study variables

\begin{tabular}{|c|c|c|c|c|c|c|c|}
\hline & $\begin{array}{l}\text { Workplace cogni- } \\
\text { tive failure }\end{array}$ & Age & Sex & Monday & Social stressors & $\begin{array}{l}\text { Sleep onset } \\
\text { latency }\end{array}$ & Sleep duration \\
\hline \multicolumn{8}{|c|}{ Workplace cognitive failure } \\
\hline Age & -0.112 & & & & & & \\
\hline Sex & $0.157^{*}$ & $-0.223^{* *}$ & & & & & \\
\hline Monday & $0.311 * *$ & 0.003 & 0.005 & & & & \\
\hline Social stressors & $0.294 * *$ & $-0.339 * *$ & $0.218 * *$ & 0.001 & & & \\
\hline Sleep onset latency & $0.120 *$ & $-0.157 *$ & 0.081 & $0.158^{*}$ & 0.034 & & \\
\hline Sleep duration & 0.010 & -0.009 & 0.067 & -0.017 & -0.077 & 0.106 & \\
\hline
\end{tabular}

$N=40$ participants assessed during, $n=198$ nights

$* p<0.05, * * p<0.01, * * * p<0.001, p$-values are one-tailed

was BodyMedia's SenseWear Armband, which is a multiaccelerometer device similar to a regular actigraph. Every minute, 2-axis oscillometric sensors assessed body movements. Data were analysed with BodyMedia software. Sleep onset latency was coded as the time participants needed to fall asleep after going to bed. Sleep duration represented the time in minutes of sleep until waking up.

We controlled our data for inaccurate measurements (e.g. malfunction of the actigraphs) by evaluating visual graphs produced by the software and by evaluating the exported raw data; such inaccurate measurements were coded as missing data. Note that naps during the day were not included in the analyses.

\subsection{Statistical Analysis}

We used the MLwiN software package [35]. In the multilevel analyses, Level 2 predictor variables were centered on the grand mean, and Level 1 predictor variables were person mean-centered. To test potential interaction effects, we included two-way and three-way interaction terms to the model. With respect to the skewed distribution of workplace cognitive failure, we used a nonparametric bootstrapping procedure to estimate the parameters in multilevel regression analyses and report Spearman's rank correlations between variables. A post hoc moderated mediation test included weekday as a moderator of the indirect path from background social stressors via sleep-onset latency to workplace cognitive failure. We used the software tool developed by Rockwood [36] that is based on SPSS-mixed models syntax. Thereby, all L1-paths of the 2-1-1- moderated mediation model were tested as fixed effects. Note that non-standardised coefficients are reported. Because of the directional hypothesis, the alpha level was set to $p<0.05$, one-tailed [37]. Demographical information on sex and age was considered as potential control variables.

\section{Results}

\subsection{Descriptive Results}

Mean sleep duration was nearly $7 \mathrm{~h}$, and mean sleep-onset time was lower than 15 min (Table 1). Background social stressors were, on average, 1.6 on a scale ranging from 1 to 4 while mean levels of workplace cognitive failure were low with 1.4 on a scale from 1 to 5 . Table 2 shows that the Spearman's rank correlation between workplace cognitive failure and social stressors was significantly positive $(\mathrm{r}(198)=0.29, p<0.01)$. Moreover, more frequent workplace cognitive failure corresponded to longer sleep-onset delay in the preceding night $(\mathrm{r}(198)=0.12, p<0.05)$ as well as to Monday (coded 1 versus other working weekdays coded $0 ; \mathrm{r}(198)=0.31, p<0.01)$. Delay in sleep onset was greater at night to Monday than on other working weekday 
Fig. 1 Mean level of workrelated cognitive failure during first half of morning work as reported at noon $(+2$ SEM)
Table 3 Test of the Monday effect: multilevel regression of workplace cognitive failure, sleep-onset latency, and sleep duration on day of work (Monday versus other workingweek days)

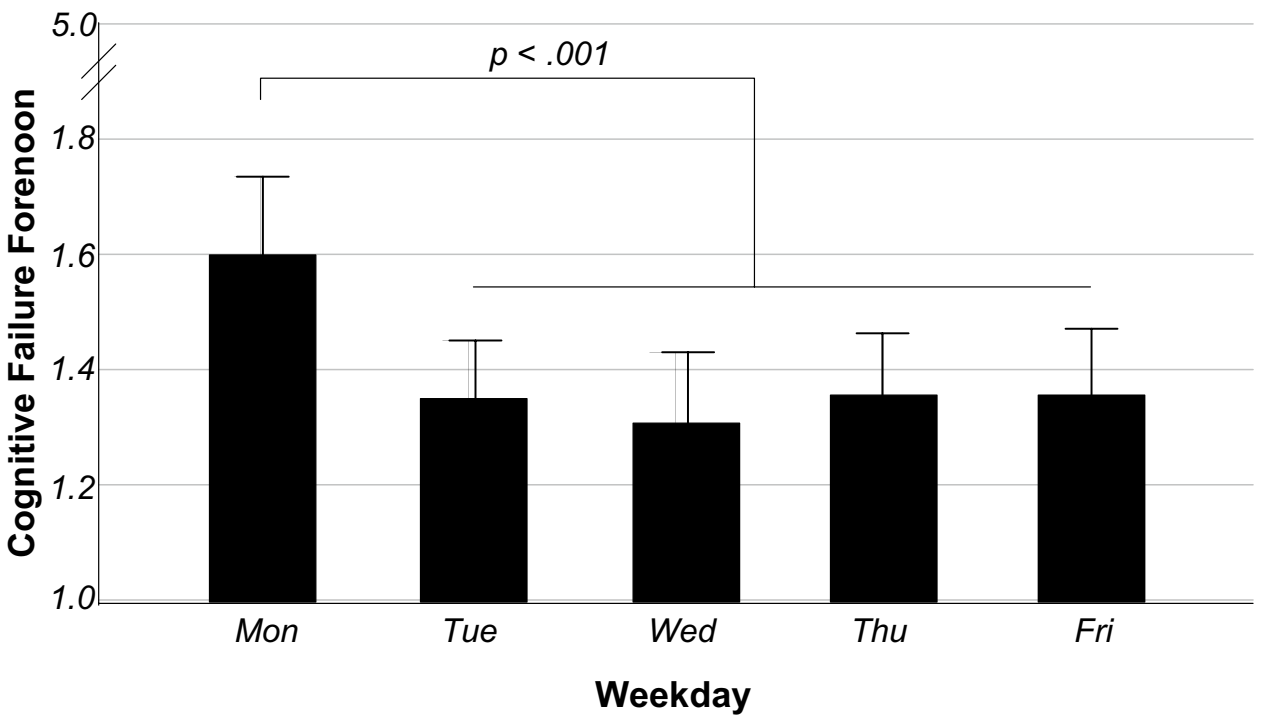

\begin{tabular}{|c|c|c|c|c|c|c|c|c|c|}
\hline & \multicolumn{3}{|c|}{ Workplace cognitive failure } & \multicolumn{3}{|c|}{ Sleep onset latency } & \multicolumn{3}{|c|}{ Sleep duration } \\
\hline & $B$ & SE & $t$ & $B$ & SE & $t$ & $B$ & SE & $t$ \\
\hline Constant & 1.2800 & 0.0750 & 17.07 & 13.4200 & 1.8360 & 7.31 & 416.0000 & 11.4800 & 36.24 \\
\hline Age & -0.0011 & 0.0041 & -0.27 & -0.1134 & 0.0976 & -1.16 & 0.0602 & 0.6199 & 0.10 \\
\hline Sex & 0.1063 & 0.1014 & 1.05 & 0.4954 & 2.4150 & 0.21 & 6.2730 & 15.3300 & 0.41 \\
\hline $\begin{array}{l}\text { Monday } \\
\quad(0=\text { no, } \\
1=\text { yes })\end{array}$ & 0.2548 & 0.0422 & $6.04 * * *$ & 4.2560 & 2.3220 & $1.83^{*}$ & -12.0400 & 10.8200 & -1.11 \\
\hline Level 2 & 0.0865 & 0.0220 & 3.94 & 21.1000 & 13.0200 & 1.62 & 1493.0000 & 508.3000 & 2.94 \\
\hline Level 1 & 0.0567 & 0.0064 & 8.89 & 172.5000 & 19.2900 & 8.94 & 3746.0000 & 418.8000 & 8.94 \\
\hline
\end{tabular}

$N=40$ participants (Level 2) assessed during, $n=198$ nights (Level 1)

${ }^{*} p<0.05,{ }^{* *} p<0.01, * * * p<0.001, p$-values are one-tailed nights $(\mathrm{r}(198)=0.16, p<0.05)$, but it was unrelated to background social stressors $(\mathrm{r}(198)=0.03, n s)$.

\subsection{Test of Hypotheses}

Figure 1 shows mean levels of workplace cognitive failure across working weekdays, with the highest levels on Mondays. Supporting our first hypothesis (H1), the multilevel analyses showed a higher cognitive failure at work on Monday than on other work days $(B=0.255, \mathrm{SE}=0.042$, $p<0.001$, Table 3 ).

In line with the second hypothesis (H2), Fig. 2 points to the longest mean sleep latencies on Sunday evening and Thursday evening. Table 3 shows Sunday night to Monday to predict a 4-min longer sleep-onset delay compared to other workday nights $(B=4.256, \mathrm{SE}=2.322, p<0.05)$. It is noteworthy that Fig. 2 shows mean levels of sleep duration at night from Sunday to Monday to also be among the lowest of the working week, but in multilevel regression analysis, no difference in sleep duration between the night from Sunday to Monday and other nights could be found ( $B=-12.04, \mathrm{SE}=10.82, \mathrm{~ns})$. Accordingly, the third hypothesis (H3) is not supported.

In accordance with hypothesis $4 \mathrm{a}$, in the second regression model of Table 4, sleep-onset latency was a significant predictor of workplace cognitive failure during the next morning $(B=0.002, \mathrm{SE}=0.001, p<0.05)$, while in contrast to hypothesis $4 \mathrm{~b}$, sleep duration was no significant predictor of workplace cognitive failure during the following morning $(B=0.0001, \mathrm{SE}=0.0003, \mathrm{~ns})$.

Supporting the fifth hypothesis (H5), higher background social stressors predict more frequent workplace cognitive failure during the following morning (Table 4; $B=0.208, \mathrm{SE}=0.035, p<0.001)$. However, the assumed interaction of social stressors and Monday (H6) in the prediction of workplace cognitive failure could not be confirmed (Table $4 ; B=-0.023, \mathrm{SE}=0.069$, ns). 


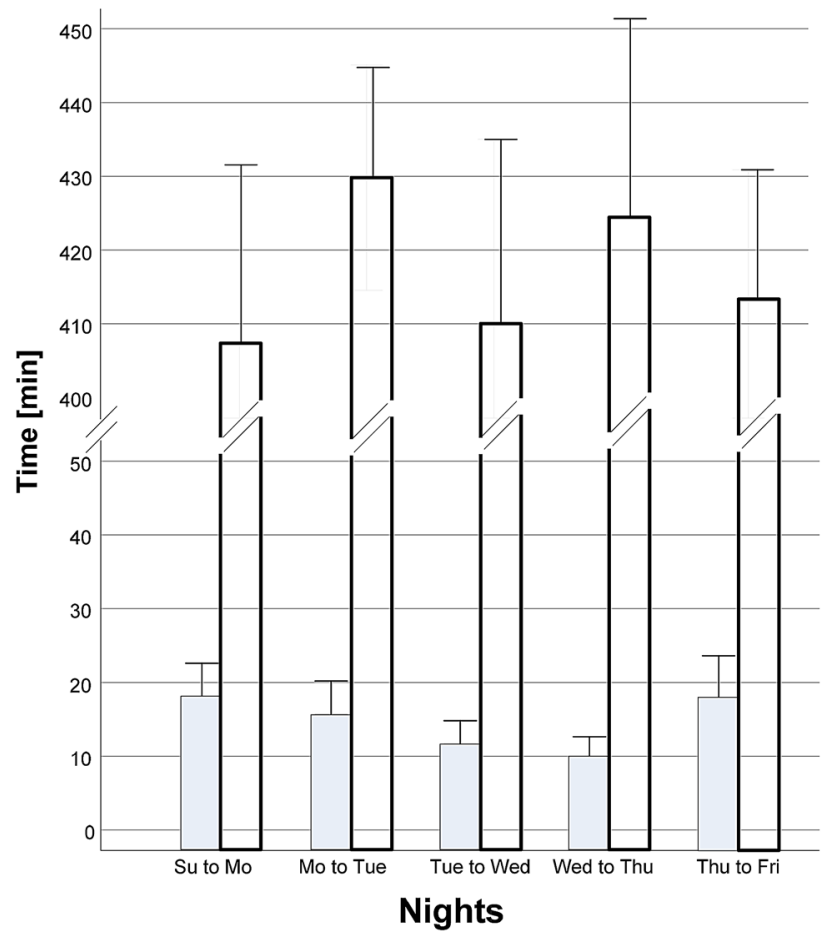

Fig. 2 Mean sleep-onset latency (grey bars) and sleep duration (+2 SEM)

Finally, the three-way interaction of background social stressors, Monday and sleep-onset latency, was also not significant (H7a: $B=-0.0014, \mathrm{SE}=0.008$, ns). The fourth regression model of Table 4 shows that no significant threeway interaction of background social stressors, Monday and sleep duration was found (H7b: $B=0.0004, \mathrm{SE}=0.0019$, ns).

\section{Discussion}

The current pilot field study sought to shed light on antecedents of the Monday effect, i.e. a higher accident risk on Monday mornings compared to other working days. Workplace cognitive failure as a meaningful proximal accidentrelated factor was confirmed to be higher on Monday morning than mornings of the following workdays. Based on the Crain's model, objectively assessed sleep-onset latency and background social stressors should limit self-regulatory resources, including working memory function and attentional control that result in workplace cognitive failure that increases accident risk [13, 19]. In line with that model, objectively assessed longer sleep-onset latency preceded higher workplace cognitive failure, and background social stressors were positively associated with workplace cognitive failure. Hence, this pilot field study, for the first time, showed workplace cognitive failure to be a close representation of the Monday effect. At the same time, sleep quantity and background social stressors did not explain the process behind the Monday effect because Monday, sleep quantity, and background social stressors were unique contributing factors, and the expected interaction effects were not confirmed. With respect to a process model that involves the weekday, background social stressors, sleep, and workplace cognitive failure, one might consider - as an alternative to interaction effects - a moderated mediation model (Fig. 3). The moderated mediation includes weekday as a moderator of the indirect path from background social stressors via sleep-onset latency to workplace cognitive failure. A post hoc test of that multilevel moderated 2-1-1-mediation model including both L1-variables as fixed effects with the software tool developed by Rockwood [36] did not confirm the indirect path (Fig. 3). The "a" path from background social stressors to sleep-onset latency did not show up. Nevertheless, many studies reported the link between background social stressors and lower sleep quality [38]. In the future, larger studies should test interaction and moderated mediation with more statistical power. The small sample size is a limitation of the current pilot study, and another limitation is the lack of daily social stressor assessment to rule out the Monday effect being due to exceptional work demands on Monday mornings. Another limitation is the lack of lifestyle assessment over the weekend. Increased alcohol consumption throughout the weekend is a potential factor involved in the Monday effect [39] and should be monitored in future studies. Greater alcohol consumption on Saturday and Sunday may interfere with sleep-onset latency on Sunday [39]. Future studies should also include risky decision-making as a cognitive function that relates to the Monday effect. Cognitive failure has been shown to relate risk-bearing behavior in sports [14], and recently, a withinperson study across seven consecutive nights with restricted sleep showed an increase in financial risk-taking [40].

\subsection{Strengths and Limitations}

In the current field study, the sample size is too small to analyse accidents or near accidents. Hence, self-reported workplace cognitive failure as an antecedent of accidents was assessed. Future studies should include at least two weeks of observation because individual sleep patterns during the weekend, especially the so-called sleeping-in pattern with longer sleep in the night time from Friday to Saturday that changes the circadian sleep rhythm, are known to predict higher sleepiness on Mondays [18]. Moreover, another limitation is the lack of private social stressor assessment over the weekend and during workdays. Sleep deprivation resulting from shorter sleep duration and longer sleep-onset latencies may change the control over emotion regulation [41]. Hence, reversed causation, i.e. sleep deprivation that fosters social stressors at work, should be estimated in further 


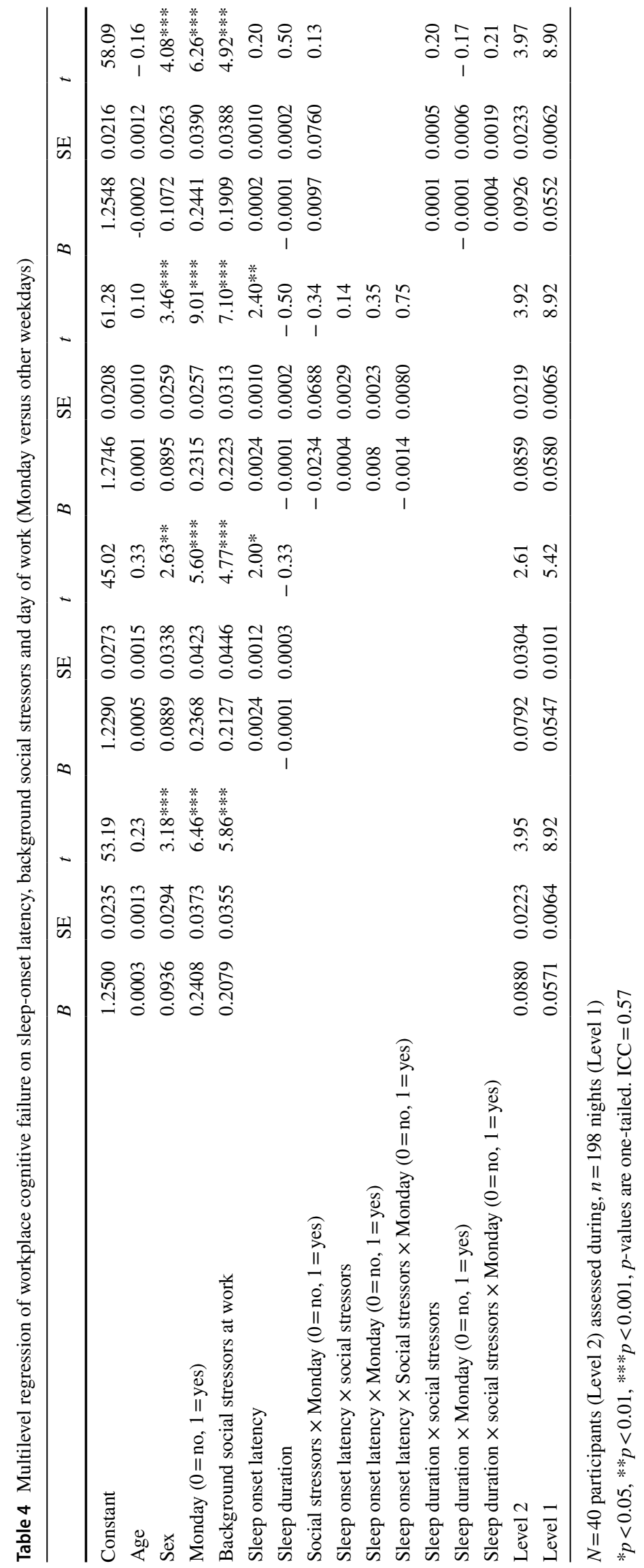


Fig. 3 Post hoc test of a moderated mediation model of the Monday effect

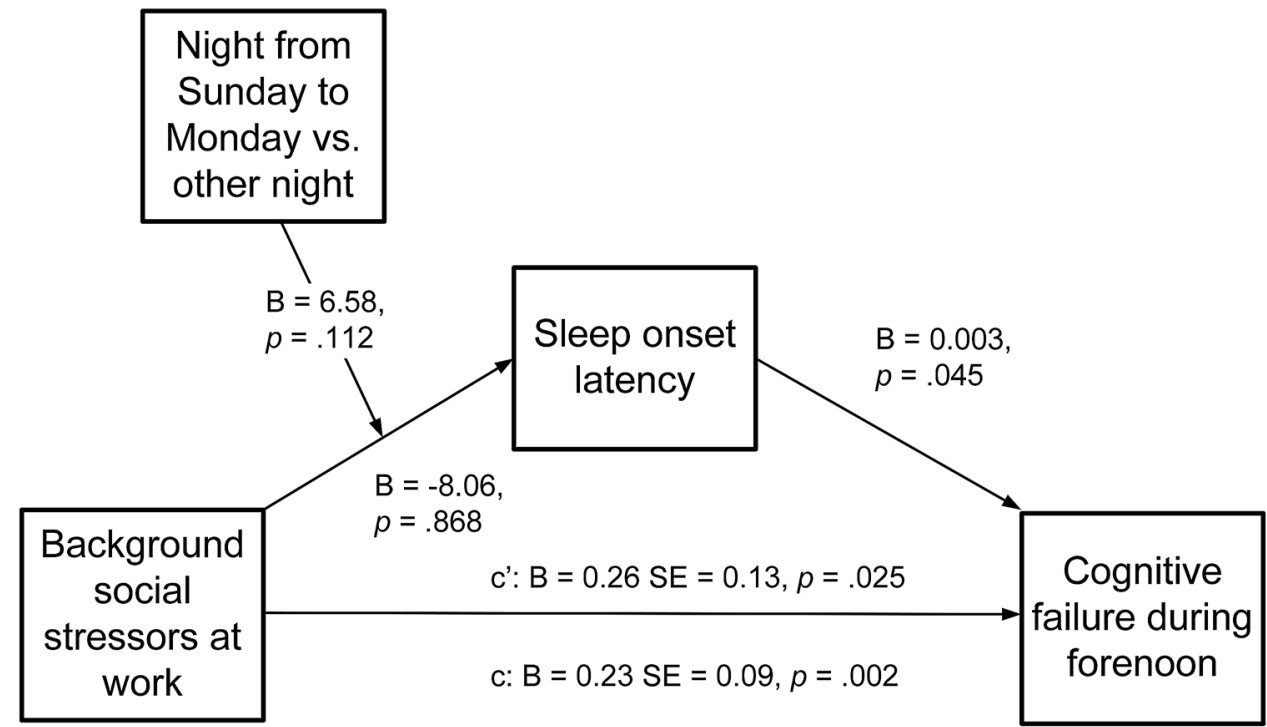

Indirect path: $\mathrm{B}=0.06, \mathrm{SE}=0.10, p=.509,90 \% \mathrm{LL}=-0.05 \quad 90 \% \mathrm{UL}=0.25$ studies. Finally, future studies should include assessment of work-related thinking throughout the weekend [42-44]. A recent meta-analysis showed work-related thinking during leisure time to be moderately associated with sleep quantity and sleep quality [45]. Thereby, the current study also has some strengths in applying an objective sleep assessment across a working week. Objective sleep assessment ruled out the mono-method bias that is a problem in many diary studies that rely completely on self-report questionnaire assessments [46].

\subsection{Theoretical and Practical Implications}

The current pilot study underlines the need to address the Monday effect by occupational health prevention. Thereby, both social work stressors and nightly sleep should be addressed. Reducing reactivity to social conflicts could also help to maintain or improve sleep [46, 47]. The person-oriented approach to sleep includes sleep extension on weekends [48] as well as online, after-work sleep training interventions (including mindfulness training) to increase sleep quality $[49,50]$. However, also education-based occupational sleep interventions have been shown to improve actigraphy-based sleep indicators [51].

\subsection{Concluding Remarks}

Short sleeping times threaten next-day performance and safety in the workplace but the processes behind need clarification $[52,53]$. We found work-related cognitive failure and sleep-onset latency in the previous night to be higher on Mondays compared to other workdays. Moreover, workrelated cognitive failure was predicted by delayed sleeponset latency and background social stressors. Reduction of social stressors at work has the potential to reduce the Monday effect.

Funding Open access funding provided by University of Bern.

\section{Compliance with Ethical Standards}

Conflict of interest The authors declare that they have no conflicts of interest. There was no funding for the study.

Ethical approval All procedures performed in studies involving human participants were in accordance with the ethical standards of the institutional and/or national research committee and with the 1964 Helsinki declaration and its later amendments or comparable ethical standards. The study received approval from the ethical committee of the responsible university faculty (Proposal Nr. 2010-08-00003). This article does not contain any studies with animals performed by any of the authors.

Informed consent Informed consent was obtained from all participants included in the study.

Open Access This article is licensed under a Creative Commons Attribution 4.0 International License, which permits use, sharing, adaptation, distribution and reproduction in any medium or format, as long as you give appropriate credit to the original author(s) and the source, provide a link to the Creative Commons licence, and indicate if changes were made. The images or other third party material in this article are included in the article's Creative Commons licence, unless indicated otherwise in a credit line to the material. If material is not included in the article's Creative Commons licence and your intended use is not permitted by statutory regulation or exceeds the permitted use, you will 
need to obtain permission directly from the copyright holder. To view a copy of this licence, visit http://creativecommons.org/licenses/by/4.0/.

\section{References}

1. Wigglesworth E. Occupational injuries by hour of day and day of week: a 20-year study. Aust NZ J Public Health. 2006;30:505-8.

2. López Arquillos A, Rubio Romero JC, Gibb A. Analysis of construction accidents in Spain, 2003-2008. J Saf Res. 2012;43:381-8.

3. Brogmus GE. Day of the week lost time occupational injury trends in the US by gender and industry and their implications for work scheduling. Ergonomics. 2007;50:446-74.

4. SUVA. Unfallstatistik: Achtung vor dem Montagmorgen. https://www.suva.ch/de-ch/die-suva/news-und-medien/medie n/2010/09/27/unfallstatistik-achtung-vor-dem-montagmorgen. Accessed 4 Apr 2019

5. SUVA. Unfallstatisitik 2017. UDM, Spezialstatistik UVG, Stichprobenergebnisse hochgerechnet VTS-ID 24638 qua 03.09.2019. https://www.unfallstatistik.ch/. Accessed 4 Apr 2019

6. McAllan FJ, Egerton-Warburton D, O'Reilly G, Weiland TJ, Jelinek GA. Planning for the future: modelling daily emergency department presentations in an Australian capital city. Emerg Med Australas. 2019;31:750-5.

7. SUVA. Ergebnisse der Unfallstatistik der zwölften fünfjährigen Beobachtungsperiode 1973-1977. https://www.google.com/ url sa $=\mathrm{t} \& \mathrm{rct}=\mathrm{j} \& \mathrm{q}=\& \mathrm{esrc}=\mathrm{s} \&$ source $=$ web $\& \mathrm{~cd}=\& \mathrm{ved}=2 \mathrm{ahUK}$ EwjqqdTb96HrAhVrMewKHS6ACpgQFjAAegQICBAB \&url=https $\% 3 \mathrm{~A} \% 2 \mathrm{~F} \% 2 \mathrm{Fwww}$.unfallstatistik.ch\%2Fd\%2Fpub lik\%2Ffuenfjb\%2Fpdf\%2FD1973_1977.pdf\&usg=AOvVaw1E1v 5Hj1KiIN2cnzg7FUcW. Accessed 4 Apr 2019

8. Elsheikh TM, Kirkpatrick JL, Fischer D, Herbert KD, Renshaw AA. Does the time of day or weekday affect screening accuracy? A pilot correlation study with cytotechnologist workload and abnormal rate detection using the Thin Prep imaging system. Cancer Cytopathol. 2010;118:41-6.

9. Roets B, Christiaens J. Shift work, fatigue, and human error: An empirical analysis of railway traffic control. J Transp Saf Secur. 2019;11:207-24.

10. Wallace JC, Chen G. Development and validation of a work-specific measure of cognitive failure: implications for occupational safety. J Occup Organ Psychol. 2005;78:615-32.

11. Elfering A, Grebner S, de Tribolet-Hardy F. The long arm of time pressure at work: Cognitive failure and nearby commuting accidents. Eur J Work Organ Psychol. 2013;22:737-49.

12. Elfering A, Grebner S, Haller M. Railway-controller-perceived mental workload, cognitive failure and risky commuting. Ergonomics. 2012;55:1463-75.

13. Brossoit RM, Crain TL, Leslie JJ, Hammer LB, Truxillo DM, Bodner TE. The effects of sleep on workplace cognitive failure and safety. J Occup Health Psychol. 2019;24:411-22.

14. Elfering A, Grebner S, Schwander L, Wattinger M. Sports after busy work: work-related cognitive failure corresponds to risk bearing and athletic injury. Psychol Writings. 2014;7:43-544.

15. Elfering A, Grebner S, Boillat C. Busy at work and absent-minded at home: mental workload, cognitive failure and domestic falls. Swiss J Psychol. 2013;72:219-28.

16. Tsai M-C. The good, the bad, and the ordinary: The day-ofthe-week effect on mood across the globe. J Happiness Stud. 2019;20:2101-24.

17. Rook JW, Zijlstra FRH. The contribution of various types of activities to recovery. Eur J Work Organ Psychol. 2006;15:218-40.
18. Taylor A, Wright HR, Lack LC. Sleeping-in on the weekend delays circadian phase and increases sleepiness the following week. Sleep Biol Rhythms. 2008;6:172-9.

19. Crain TL, Brossoit RM, Fisher GG. Work, nonwork, and sleep (WNS): a review and conceptual framework. J Bus Psychol. 2018;33:675-97.

20. Martin M. Cognitive failure: everyday and laboratory performance. Bull Psychon Soc. 1983;21:97-100.

21. Broadbent DE, Cooper PF, Fitzgerald P, Parkes KR. The cognitive failures questionnaire (CFQ) and its correlates. Br J Clin Psychol. 1982;21:1-16.

22. Elfering A, Grebner S, Ebener C. Workflow interruptions, cognitive failure and near-accidents in health care. Psychol Health Med. 2015;20:139-47.

23. Devereux J, Rydstedt LW, Cropley M. An exploratory study to assess the impact of work demands and the anticipation of work on awakening saliva cortisol. Psychol Rep. 2011;108:274-80.

24. Semmer NK, Jacobshagen N, Meier LL, Elfering A. Occupational stress research: The 'stress-as-offense-to-self' perspective. In: Houdmont J, McIntyre S, editors. Occupational health psychology: European perspectives on research, education and practice. Castelo da Maia: ISMAI Publishing; 2007. p. 43-60.

25. Hockey GRJ. A motivational control theory of cognitive fatigue. In: Ackerman PL, editor. Cognitive fatigue: multidisciplinary perspectives on current research and future applications. Washington: American Psychological Association; 2011. p. 167-188.

26. Kottwitz MU, Gerhardt C, Schmied S, Elfering A. Sleep, work stress and headache in printing business: an actigraphy study. Sleep Vigilance. 2019;3:9-15.

27. Pereira D, Elfering A. Social stressors at work and sleep quality on sunday night - the mediating role of psychological detachment. J Occup Health Psychol. 2014;19:85-95.

28. Pereira D, Gross S, Elfering A. Social stressors at work, sleep, and recovery. Appl Psychophysiol Biofeedback. 2016;41:93-101.

29. Frese M, Zapf D. Eine Skala zur Erfassung von sozialen Stressoren am Arbeitsplatz [A measure of social stressors at work]. Z Arbeitswiss. 1987;41:134-42.

30. De Souza L, Benedito-Silva AA, Pires MLN, Poyares D, Tufik S, Calil HM. Further validation of actigraphy for sleep studies. Sleep. 2003;26:81-4.

31. Sadeh A. The role and validity of actigraphy in sleep medicine: An update. Sleep Med Rev. 2011;15:259-67.

32. Kushida CA, Chang A, Gadkary C, Guilleminault C, Carrillo O, Dement WC. Comparison of actigraphic, polysomnographic, and subjective assessment of sleep parameters in sleep-disordered patients. Sleep Med. 2001;2:389-96.

33. Morgenthaler T, Alessi C, Friedman L, Owens J, Kapur V, Boehlecke B, Brown T, Chesson A, Coleman J, Lee-Chiong T, Pancer J, Swick TJ. Practice parameters for the use of actigraphy in the assessment of sleep and sleep disorders: an update for 2007. Sleep. 2007;30:519-29.

34. Germain A, Buysse DJ, Kupfer DJ. Preliminary validation of a new device for studying sleep, presented at the SLEEP Meeting 2006, Salt Lake City, UT.

35. Rasbash J, Steele F, Browne WJ, Goldstein H, Charlton C. A user's guide to MLwiN. London: Multilevel models project, Institute of Education, University of London; 2015.

36. Rockwood NJ, Hayes AF. MLmed: An SPSS macro for multilevel mediation and conditional process analysis. Poster presented at the annual meeting of the Association of Psychological Science (APS), Boston, MA; 2017.

37. Wonnacott TH, Wonnacott RJ. Introductory statistics for business and economics. New York: Wiley; 1984.

38. Pereira D, Gerhardt C, Kottwitz MU, Elfering A. Occupational sleep medicine: Role of social stressors. In: Pandi-Perumal SR, 
Narasimhan M, Kramer M, editors. Sleep and psychosomatic medicine. 2nd ed. Basingstoke: Taylor \& Francis; 2016. p. $57-84$.

39. Heeb JL, Gmel G, Rehm J, Mohler-Kuo M. Exploring daily variations of drinking in the Swiss general population. A growth curve analysis. Int J Meth Psych Res. 2008;17:1-11.

40. Maric A, Montvai E, Werth E, Storz M, Leemann J, Weissengruber S, Ruff CC, Huber R, Poryazova R, Baumann CR. Insufficient sleep: enhanced risk-seeking relates to low local sleep intensity. Ann Neurol. 2017;82:409-18.

41. Tamm S, Schwarz J, Thuné H, Kecklund G, Petrovic P, Åkerstedt T, Fischer H, Lekander M, Nilsonne G. Effects of partial sleep deprivation on emotional contagion in humans: a combined fMRI and EMG study in young and older individuals. https://psyarxiv. com/k6acx. Accessed 10 Jan 2020

42. Ben Simon E, Rossi A, Harvey AG, Walker MP. Overanxious and underslept. Nat Hum Behav. 2020;4:100-10.

43. Sonnentag $\mathrm{S}$. The recovery paradox: portraying the complex interplay between job stressors, lack of recovery, and poor well-being. Res Organ Behav. 2018;38:169-85.

44. Weigelt O, Gierer P, Syrek CJ. My mind is working overtimeTowards an integrative perspective of psychological detachment, work-related rumination, and work reflection. Int J Environ Res Public Health. 2019;16:2987-3013.

45. Clancy F, Prestwich A, Caperon L, Tsipa A, O'Connor DB. The association between perseverative cognition and sleep in non-clinical populations: a systematic review and meta-analysis. Health Psychol Rev. 2020;2020:1-64.

46. Semmer NK, Grebner S, Elfering A. Beyond self-report: using observational, physiological, and event-based measures in research on occupational stress. In: Perrewé PL, Ganster DC, (eds.) Emotional and physiological processes and positive intervention strategies. Research in Occupational Stress and Wellbeing; Amsterdam: JAI; 2004. pp. 205-63.

47. Herr R, Barrech A, Riedel N, Gündel H, Angerer P, Li J. Longterm effectiveness of stress management at work: effects of the changes in perceived stress reactivity on mental health and sleep problems seven years later. Int J Environ Res Public Health. 2018;15:255-69.

48. Kubo T, Takahashi M, Sato T, Sasaki T, Oka T, Iwasaki K. Weekend sleep intervention for workers with habitually short sleep periods. Scand J Work Environ Health. 2011;37:418-26.

49. Behrendt D, Ebert DD, Spiegelhalder K, Lehr D. Efficacy of a self-help web-based recovery training in improving sleep in workers: Randomized controlled trial in the general working population. J Med Internet Res. 2020;22:e13346.

50. Thiart H, Lehr D, Ebert DD, Berking M, Riper H. Log in and breathe out: internet-based recovery training for sleepless employees with work-related strain - results of a randomized controlled trial. Scand J Work Environ Health. 2015;41:164-74.

51. Nakada Y, Sugimoto A, Kadotani H, Yamada N. Verification of effect of sleep health education program in workplace: a quasirandomized controlled trial. Ind Health. 2018;56:20-9.

52. Czeisler CA. Duration, timing and quality of sleep are each vital for health, performance and safety. Sleep Health. 2015;1:5-8.

53. Rosekind MR, Gregory KB, Mallis MM, Brandt SL, Seal B, Lerner D. The cost of poor sleep: workplace productivity loss and associated costs. J Occup Environ Med. 2010;52:91-8.

Publisher's Note Springer Nature remains neutral with regard to jurisdictional claims in published maps and institutional affiliations. 